\title{
Strength Characteristics of Polyurethane (PU) With Modified Sand
}

\author{
Sidek N. ${ }^{1 *}$, Mohamed K. ${ }^{2}$, M.Jais I.B. ${ }^{2}$ and Abu Bakar I.A. ${ }^{2}$ \\ ${ }^{1}$ Post Graduate Student, UiTM Shah Alam, Malaysia \\ ${ }^{2}$ Senior Lecturer, UiTM Shah Alam , Malaysia \\ norbayasidek@gmail.com
}

\begin{abstract}
Keywords: Polyurethane, shear strength, Unconfined Compression Test (UCT), ground improvement
\end{abstract}

\begin{abstract}
Soil stabilisation is defined as a technique to improve the engineering characteristics in order to improve the parameters such as shear strength, compressibility, density, hydraulic conductivity. There are many techniques that can be used for different purposes by enhancing some aspects of soil behaviour and improve the strength and properties of soil. One of the cheapest techniques is by using Polyurethane grout, which is workable for construction and enhances the performance of soil compressive strength. Polyurethane (PU) foam is non-toxic, having an indefinite life span and non-environment unfriendly. PU is a chemical substance that normally used in polymer industries for instance resilience foam seating, rigid foam insulation panels and microcellular foam seals. In this research, different percentages of PU content are mixed with sand to test the compressive strength of modified sand. The compressive strength of sand is determined by conducting the Unconfined Compression Test (UCT) with the mold samples of 50mm diameter and $100 \mathrm{~mm}$ height. The test determines the compressive strength and generates the stress-strain relationship of the modified sand. It is shown that the compressive strength of modified sand will gradually increase with an increasing PU content percentage (varying from $10 \%(20 \mathrm{kPa})-95 \%$ $(500 \mathrm{kPa})$. Conclusively, this research could be used as the benchmark of ground improvement technique.
\end{abstract}

\section{Introduction}

Most of the skyscrapers as such Tower of Pisa and Malaysian Leaning Tower of Teluk Intan, Perak are well-known due to their soil settlement awareness besides the aesthetic values of architectural aspects. Settlement is referred to the movement of ground surface in the vertical downward displacement at the base of foundation. There are many factors that may contribute to the ground movements which prone to the structural failures. Most countries confronted with the unstable soil problems including Malaysia which causes an increment in construction costs for the treatment of unstable soil. The needs for the best solution of soil treatment for construction is studied to ensure the safety and achieve an economical design. It is proved that the soil replacement time frame is significantly reduced with the implementation of ground improvement techniques.

\section{Theoretical Background}

Theoretically, this research is to study the ground improvement technique using PU as a stabilising agent of the soil. Pressure grout is one of the methods being used to improve the ground. The method is performed by injecting the cement into the ground to fill up the voids. Nowadays, PU has been used as an alternative to cement in grouting. The PU grouting procedure is identical to the conventional cement procedure wherein the PU liquid is injected into the ground and filling up the voids between the soil particles.

In addition, with the use of PU the bearing capacity of the soil is improved due to the expansion of voids between the soil particles. Furthermore, the lightweight characteristics of PU allow a reduction of settlement rate and expansion characteristics of PU able to lift up the ground soil. 
Fig. 1 shows the schematic diagram of PU injection procedure at field. However in this paper is focused on determining the compressive strength of modified sand using Unconfined Compression test (UCT) in laboratory work.

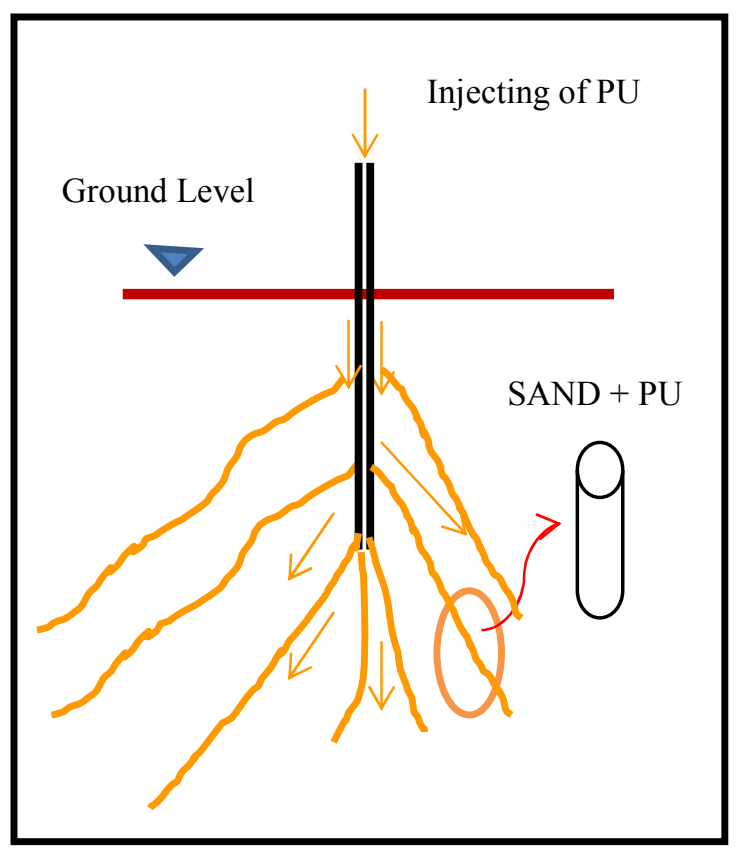

Fig.1 : The schematic diagram of PU injection procedure

\section{Materials and Methods}

This section summarizes the procedures of UCT and materials needed for the experimental work.

This research is a laboratory based using PU and course sand which conducted with several laboratory testings.All the physical properties tests are conducted based on British Standard. Three (3) physical properties on strength characteristics are investigated; i.e. the moisture content, the specific gravity and the particle size distribution.

Engineering properties test which is Unconfined Compressive Test (UCT) have been conducted to investigated the compressive strength of modified sand.

Each sample is prepared based on:

a) PU ratio (1:1)

b) interval of $5 \%$ PU percentage (10\% to $95 \%)$

c) $50 \mathrm{~mm}$ diameter and $100 \mathrm{~mm}$ height

The graph of Compressive Strength vs Percentage of PU in sand are being plotted to show the compressive strength of modified sand.

\section{Results and Discussion}

In this section, we will quantify the main parameters (via physical properties and engineering properties test) and their interactions that play an important role in influencing the strength characteristics of PU mixtures. 


\section{Physical Properties Test}

Below are the results of physical properties tests that have been conducted;

a) Moisture content

The average moisture content of course sand from the four (4) samples tested is $0.195 \%$.

b) Particle Size Distribution

The percentage of gravel is $0.51 \%$, sand is $99.22 \%$, silt is $0.27 \%$ and $0 \%$ of clay. Proportion of sand is $4 \%$ fine sand, $19 \%$ medium sand and $77 \%$ course sand. The $\mathrm{Cu}$ and $\mathrm{Cg}$ of this soil is 3.32 and 1.29 respectively. To be concluded, the soil classification of the soil is poorly graded SAND, $\mathrm{SP}$.

c) Specific Gravity

The average particle density is $2.66 \mathrm{Mg} / \mathrm{m}^{3}$ and the type of soil is Silty Sand.

\section{Engineering Properties Test (UCT)}

Table 1 shows the compressive strengths of modified sand with respect to the percentage of PU content. These values are obtained from the maximum values of compressive strength of modified sand in compressive strength-axial strain relationship datas.

Table 1: Compressive strength of sand subjected to percentage of PU

\begin{tabular}{|l|l|l|l|}
\hline \multirow{2}{*}{$\begin{array}{l}\text { PERCENTAGE } \\
\text { OF PU IN SAND } \\
(\%)\end{array}$} & \multicolumn{3}{|c|}{ COMPRESSIVE STRENGTH (kPa) } \\
\cline { 2 - 4 } & $\mathbf{A}$ & $\mathbf{B}$ & $\mathbf{C}$ \\
\hline 10 & 24.70 & 7.60 & 13.50 \\
\hline 15 & 12.00 & 12.70 & 14.30 \\
\hline 20 & 22.80 & - & 12.60 \\
\hline 25 & 22.80 & 24.50 & 28.30 \\
\hline 30 & 47.30 & 42.50 & 57.10 \\
\hline 35 & 3.30 & 26.40 & 19.50 \\
\hline 40 & 102.80 & 71.00 & 128.70 \\
\hline 45 & 6.50 & 42.90 & 16.10 \\
\hline 50 & 130.10 & 113.30 & 111.50 \\
\hline 55 & 43.30 & 52.20 & 33.60 \\
\hline 60 & 189.50 & 238.50 & 92.20 \\
\hline 65 & 62.50 & 76.50 & 72.20 \\
\hline 70 & 278.80 & 240.20 & 229.80 \\
\hline 75 & 81.90 & 126.00 & 161.50 \\
\hline 80 & 168.90 & 234.80 & 337.20 \\
\hline 85 & 97.90 & 201.60 & 198.70 \\
\hline 90 & 320.30 & 254.30 & 590.80 \\
\hline 95 & 317.10 & 133.70 & 121.40 \\
\hline 100 & 488.80 & 555.30 & 508.20 \\
\hline
\end{tabular}

A graph is plotted to illustrate the compressive strength relationship of modified sand as shown in Fig. 2. The average values are utilized in order to give the best fit of correlation between the compressive strength and the percentage of PU content. It is shown that the undrained compressive 
strength and maximum compressive stress profile are experienced by this modified sand with 590 $\mathrm{kPa}$.

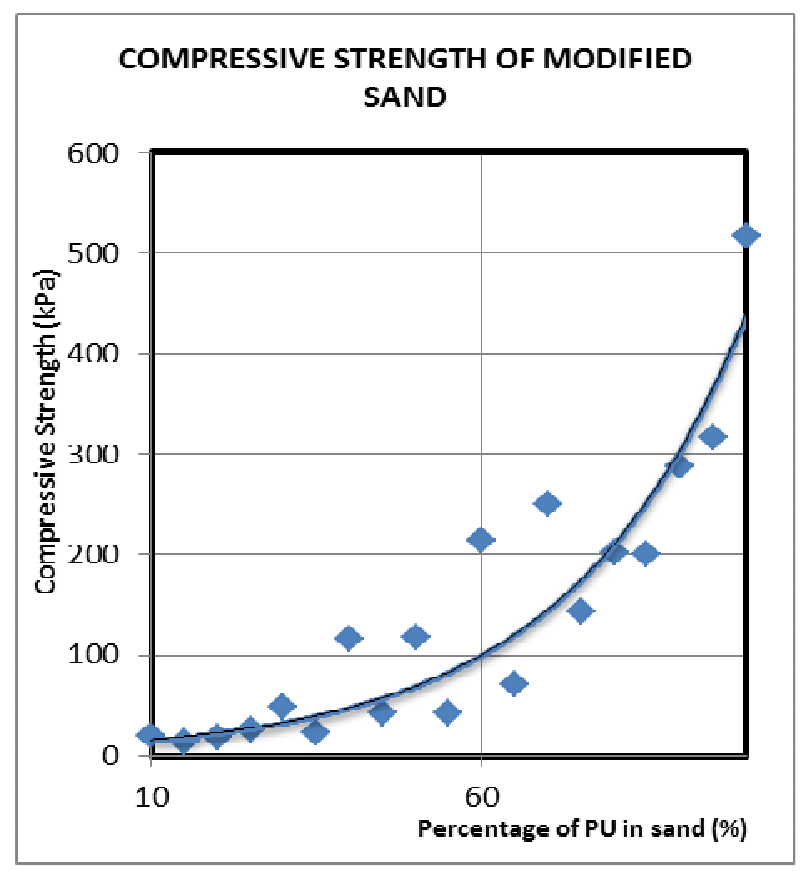

Fig. 2: Compressive Strength of Modified Sand

According to Fig. 2, it is depicted that the compressive strength values gradually increases as percentage of PU content increases. Theoretically, the mixtures of PU liquid and modified sand will change the sand characteristics which yield strength performance in the sand particles.

This can be proven with the results of the highest value of compressive strength at the point of the highest PU content. A better compressibility characteristic is obtained with the use of Polyurethane foam in soil composition.

\section{Conclusion}

This research has presented an experimental work to define the strength characteristics of modified sand with PU content variations. The so-obtained modified sand shows an acceptable strength performance with considerable values of physical properties; i.e. the moisture content, the particle size distribution and the specific gravity values. The course sand used in this research has been classified as silty sand with $2.66 \mathrm{Mg} / \mathrm{m} 3$ of specific gravity. The strength of modified sand subjected to PU percentage was determined accordingly. The engineering properties of modified sand are being determined by conducting the unconfined compression test (UCT). In light of this, the compressive strength of modified sand is determined and it is observed that the compressive strength of modified sand increases as the percentage of PU content increases.

\section{References}

[1] M. Budhu, Soil Mechanics and Foundations, John Wiley \& Sons, INC, United States of America, Edition 3. (2011).

[2] S. Gopalakrishnana, and R. Sujathaa. "Research Journal of Pharmaceutical, Biological and Chemical Sciences "Ageing studies ofcardanol based polyurethanes.Volume 2 Issue 3 (2011). Page No. 1069

[3] K.H. Head, Manual of Soil Laboratory Testing, Volume 3: Effective Stress Tests, Halsted Press, John Wiley \& Sons, U.S.A and Canada, Edition 3. (1980). 
[4] C. Hepburn, Polyurethane Elastomer, Elsevier Applied Science. London, New York (1992).

[5] S. Kazemian and B.B.K. Huat, A Review of Stabilization of Soft Soil by Injection of Chemical Grouting. Australian J, Basic Application, Sci, 4(12) (2009):p5862-5868.

[6] J.M. Mitchell and F.M. Jardine. A Guide to Ground Treatment,CIRIA (2002). C573 ISBN 0 86017:573.

[7] A. Naudts. Research Project Fort Cady Minerals: Chemical Resistance of Modified Cementbased Grout and Polyurethane Grouts Accelerated Ageing Test, (1990). Unpublished.

[8] S. Norbaya, M. Kamaruzzaman, M.J. Ismacahyadi Bagus and M. Faiz. "Environmental and Sustainable Technology Using Polyurethane Foam" Annual Conference on Civil Engineering (March 14-16 Phuket, Thailand) A1403-436. (2014). 